\title{
BioOne

\section{Development of Preimaginal Stages of Haemagogus leucocelaenus (Diptera: Culicidae) in Laboratory Conditions}

Author(s): Aline Tátila-Ferreira, Daniele de Aguiar Maia, and Jeronimo Alencar

Source: Entomological News, 127(2):142-150.

Published By: The American Entomological Society

https://doi.org/10.3157/021.127.0209

URL: http://www.bioone.org/doi/full/10.3157/021.127.0209

BioOne (www.bioone.org) is a nonprofit, online aggregation of core research in the biological, ecological, and environmental sciences. BioOne provides a sustainable online platform for over 170 journals and books published by nonprofit societies, associations, museums, institutions, and presses.

Your use of this PDF, the BioOne Web site, and all posted and associated content indicates your acceptance of BioOne's Terms of Use, available at www.bioone.org/page/terms of use.

Usage of BioOne content is strictly limited to personal, educational, and non-commercial use. Commercial inquiries or rights and permissions requests should be directed to the individual publisher as copyright holder. 


\title{
DEVELOPMENT OF PREIMAGINAL STAGES OF HAEMAGOGUS LEUCOCELAENUS (DIPTERA: CULICIDAE) IN LABORATORY CONDITIONS ${ }^{1}$
}

\author{
Aline Tátila-Ferreira, ${ }^{2,3}$ Daniele de Aguiar Maia, ${ }^{2}$ and Jeronimo Alencar ${ }^{2,4}$
}

\begin{abstract}
The objective of this study was to provide new insights on the egg-to-adult biological cycle and hatching rate of eggs of Haemagogus leucocelaenus, a species that transmits wild-type yellow fever in Brazil. Eggs were collected using oviposition traps, "ovitraps," in a fragment of the Atlantic Forest in Rio de Janeiro, Brazil, in October (Experiment 1) and November (Experiment 2), 2015. Thereafter, the eggs were subjected to 16 immersions, to test hatching rate and evaluate the average development time. $\mathrm{Hg}$. leucocelaenus individuals kept in a climate-controlled chamber $\left(28^{\circ}\right.$ $\pm 1^{\circ} \mathrm{C}$ ) showed an average development period of $10.44 \pm 0.70 \mathrm{~d}$, from the start of larval stage to adulthood. Immersion viability was $49.8 \%$ and $18.2 \%$ for Experiments 1 and 2, respectively. In both experiments, the hatching peak occurred during the first immersion, where $26 \%$ and $15 \%$ of eggs hatched in Experiments 1 and 2, respectively. These results provide new insights into the biology of $\mathrm{Hg}$. leucocelaenus.
\end{abstract}

KEYWORDS: Culicidae; Haemagogus; eggs; development cycle; hatching rate

The genus Haemagogus (Williston, 1896) includes 28 species, broadly distributed throughout Central and South America. Some species of Haemagogus are important in transmitting yellow fever and Mayaro viruses. In addition, the mosquitoes may play a role in the transmission of dengue fever virus (Marcondes and Alencar, 2010).

Haemagogus leucocelaenus (Dyar \& Shannon, 1924) is a diurnally active forest species, whose preferred habitat is tree crowns (Forattini et al., 1988; Chadee et al., 1995). Its geographical distribution extends from Trinidad to southern Brazil and northern Argentina, and the species has been identified as a primary vector of wild-type yellow fever in southeastern Brazil. This species has gained increasing notoriety owing to its medical significance in transmitting other arboviruses (Arnell, 1973), especially when serotype 1 infections of dengue virus started to be reported in the state of Bahia, Brazil (Figueiredo et al., 2010).

The resistance of $\mathrm{Hg}$. leucocelaenus eggs to desiccation allows them to survive in harsh conditions. Culicidae include a number of genera with eggs that are highly resistant to dry periods, such as Aedes (Meigen, 1818), Ochlerotatus (Lynch Arribálzaga, 1891), Psorophora (Robineau-Desvoidy, 1827), Haemagogus (Williston, 1896) and Opifex (Hutton, 1902), (Clements, 1992; Juliano and Lounibos, 2005). In contrast, genera that complete their larval stage in temporarily flooded environments such as tree hollows or cut bamboo are susceptible to

\footnotetext{
${ }^{1}$ Received on October 14, 2016. Accepted on March 1, 2017.

${ }^{2}$ Diptera Laboratory, Oswaldo Cruz Institute (Fiocruz), Rio de Janeiro, Brazil. E-mails: line. tatila@hotmail.com; dani.aguiar.maia@gmail.com

${ }^{3}$ Post-graduate program, Stricto Sensu in Animal Biology, Institute of Biology, Federal Rural University of Rio de Janeiro, Seropédica, Rio de Janeiro, Brazil.

${ }^{4}$ Corresponding author E-mail: jalencar@ioc.fiocruz.br
} 
humidity fluctuations and desiccation. Thus, desiccation resistance improves reproductive success (Vinogradova, 2007). In addition, it is known that mosquito species with drought-tolerant eggs are more widely dispersed. Therefore, desiccation resistance in eggs has enabled species of Culicidae to expand their ranges into previously uninfested geographical regions. This important ecological attribute has implications for dispersion and transmission of mosquito-borne illnesses such as yellow and dengue fever, among others (Juliano and Lounibos, 2005).

With the objective to provide new insights into the egg-to-adult development of $\mathrm{Hg}$. leucocelaenus, this study provides data on egg hatching rates, average development time, and mortality indices from the initial larval stages to eclosion of adults.

\section{METHODS}

\section{Description of the study field}

The populations studied came from Campus Fiocruz da Mata Atlântica (CFMA), which covers an area of approximately 500 hectares, located in the western zone of the municipality of Rio de Janeiro, State of Rio de Janeiro, S $22^{\circ} 56^{\prime}$ and $\mathrm{W} 043^{\circ} 25^{\prime}$. The western portions of the campus consist of a nature reserve, harboring a secondary forest dominated by vegetation typical of the Atlantic Forest ('Mata Atlântica') in Brazil. The specific vegetation cover-type of this forest is classified as Dense Ombrophilous Forest. A wide diversity of wild animals inhabit the reserve, including nonhuman primates, sloths (Folivora), snakes (Ophidia), opossums (Didelphimorphia), armadillos (Cingulata), lizards (Sauria), toucans (Piciformes), and parrots (Psittaciformes). Most of these animals are sometimes observed in surrounding inhabited areas (Fiocruz, 2010).

Eight biotopes have been described in the campus area: Atlantic forest (secondary forest located above $100 \mathrm{~m}$ elevation), forest undergoing regeneration (secondary, arboreal, and dense forest), patches of trees (shrubby, arboreal vegetation), subsistence cultivation areas, pasture or weed-dominated areas (grass, some shrubs, and small trees), rocky outcrops, forested wetlands (tree groupings with possible flooding), and urbanized or deforested areas (sparsely vegetated and developed areas) (Fiocruz, 2010).

\section{Collection and processing of eggs}

Following the methodology proposed by Silver (2008), eggs were collected with ovitraps made from an uncovered, 1-L matte black pot with four pieces of Eucatex hardboard $(2.5 \mathrm{~cm} \times 14 \mathrm{~cm})$, attached vertically to the inside of the trap with "CLIPS." Water and leaf litter were put in the pot with the intention of mimicking natural egg-laying habitat (Fay and Perry, 1965; Fay and Eliason, 1966). The traps were randomly installed, at a height of 1 to $8 \mathrm{~m}$ from ground 
level, placed in the forest and monitored throughout October and November of 2015. The hardboard was replaced every two weeks. The collected hardboard was identified relative to its location, numbered sequentially, and then transported in a humidified chamber to the Diptera Laboratory of the Oswaldo Cruz Institute.

Positive cardboards, i.e., those containing eggs, were sorted in the laboratory. The eggs were then counted and immersed in transparent trays containing MiliQ ${ }^{\circledR}$ water. The trays were then placed in a greenhouse for $3 \mathrm{~d}$ with a regulated thermoperiod and photoperiod: temperature of $28^{\circ} \pm 1^{\circ} \mathrm{C}$, relative humidity of $75 \%-90 \%$ and photoperiod of $14 \mathrm{~h}$. Next, the eggs were placed on dry trays for approximately 3-4 d outside the greenhouse and then re-immersed to enable the eggs to successfully reach the end of their embryonic development stage.

When larvae reached the adult stage, a stereoscopic microscope was used to examine the morphological characteristics and identify mosquitoes to the species level, using dichotomous keys of Arnell (1973), Forattini (2002), and Marcondes and Alencar (2010). After identifying to species, specimens were deposited in the Oswaldo Cruz Institute Entomological Collection, Fiocruz, entitled: "Mata Atlântica Collection - Rio de Janeiro."

The eggs from October and November were labeled as "Experiment 1" and "Experiment 2" respectively. To compare differences in hatching rates by immersion, the Williams $\left(\mathrm{X}_{\mathrm{W}}\right)$ average was used, following the definitions of Haddow $(1954 ; 1960)$.

In order to observe the average length of the developmental stages of $\mathrm{Hg}$. leucocelaenus, 20 recently hatched larvae were collected from the CFMA, during the period when hatching rate was at maximum. The mosquito larvae were then transferred individually to plastic grow-out containers $3 \mathrm{~cm}$ in diameter and $6 \mathrm{~cm}$ in height and fed crushed and sifted fish feed (Tropi-Fish ${ }^{\circledR}$ ), applied directly into the water. Daily care was provided until the adult stage was reached. Statistical data analysis was performed using the Mann-Whitney test, adopting a significance level of $\alpha=0.05$.

\section{RESULTS}

A total of 875 eggs were collected, of which 323 (36.9\%) hatched. Of the 518 eggs collected in October (Experiment 1), the viability rate was $49.8 \%$, whereas the viability rate was $18.2 \%$ for the 357 eggs collected in November (Experiment 2 ). However, the difference between months was not statistically significant ( $\mathrm{p}=$ 0.06 ).

The hatching rate of eggs also varied between Experiments 1 and 2. After undergoing 15 immersions, a hatching rate of $26 \%$ to $63 \%$ was observed in Experiment 1 and $15 \%$ to $19 \%$ in Experiment 2 (Fig. 1). The cumulative average and the Williams average of the incubated proportion after the immersions are shown in Fig. 1. 


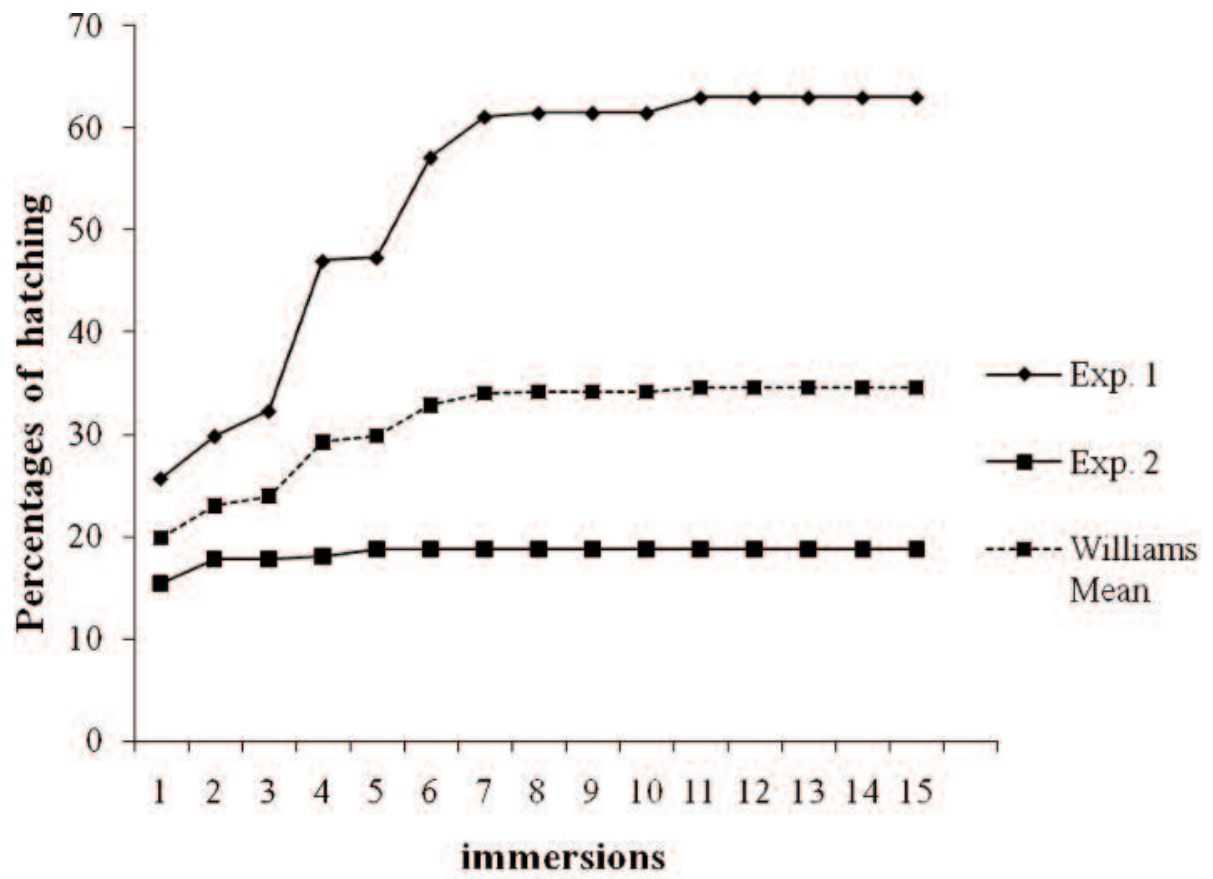

Fig. 1. Cumulative effect of multiple immersions of eggs of Hg. leucocelaenus specimens collected in ovitraps at the CFMA, Rio de Janeiro, Brazil, during October and November 2015.

In Experiment 1, the period of peak hatching occurred during the 1st immersion, when $26 \%$ of the eggs hatched, followed by the 4th (15\%), 6th (10\%), 2nd and 7 th (both $4 \%$ ) immersion. In fact, hatching was detected over 11 immersions, with $2 \%$ of eggs hatching during the last immersion. The hatching peak in Experiment 2 also occurred in the 1 st immersion, with a rate of $15 \%$ of eggs hatched, followed by the 2nd (2\%), and 5th (1\%) immersion. In general, after the 7th immersion (Experiment 1) and 5th immersion (Experiment 2), the proportion of hatched eggs declined abruptly (Fig. 2).

Among the 20 larvae monitored to the adult stage, one died in the 3rd instar and one in the 4th instar. The 18 remaining larvae completed their life cycles. Among these, 5 were female and 13 were male. The total developmental period varied between 9 and $11 \mathrm{~d}$, while the average duration of the cycles was $10.44 \pm$ $0.70 \mathrm{~d}$. The duration of each development stage was as follows: first instar, the average was $1 \pm 0.00$ ( 1 day); second instar, the average was $1.17 \pm 0.38(1-2 \mathrm{~d})$; third instar, the average was $1.17 \pm 0.38(1-2 \mathrm{~d})$; fourth instar, the average was $3.66 \pm 0.77$ ( $3-5 \mathrm{~d})$; and pupal stage, the average was $2.44 \pm 0.86(1-4 \mathrm{~d})$. The average duration of the life cycle did not reveal a significant difference between males and females $(p=0.16)$. 


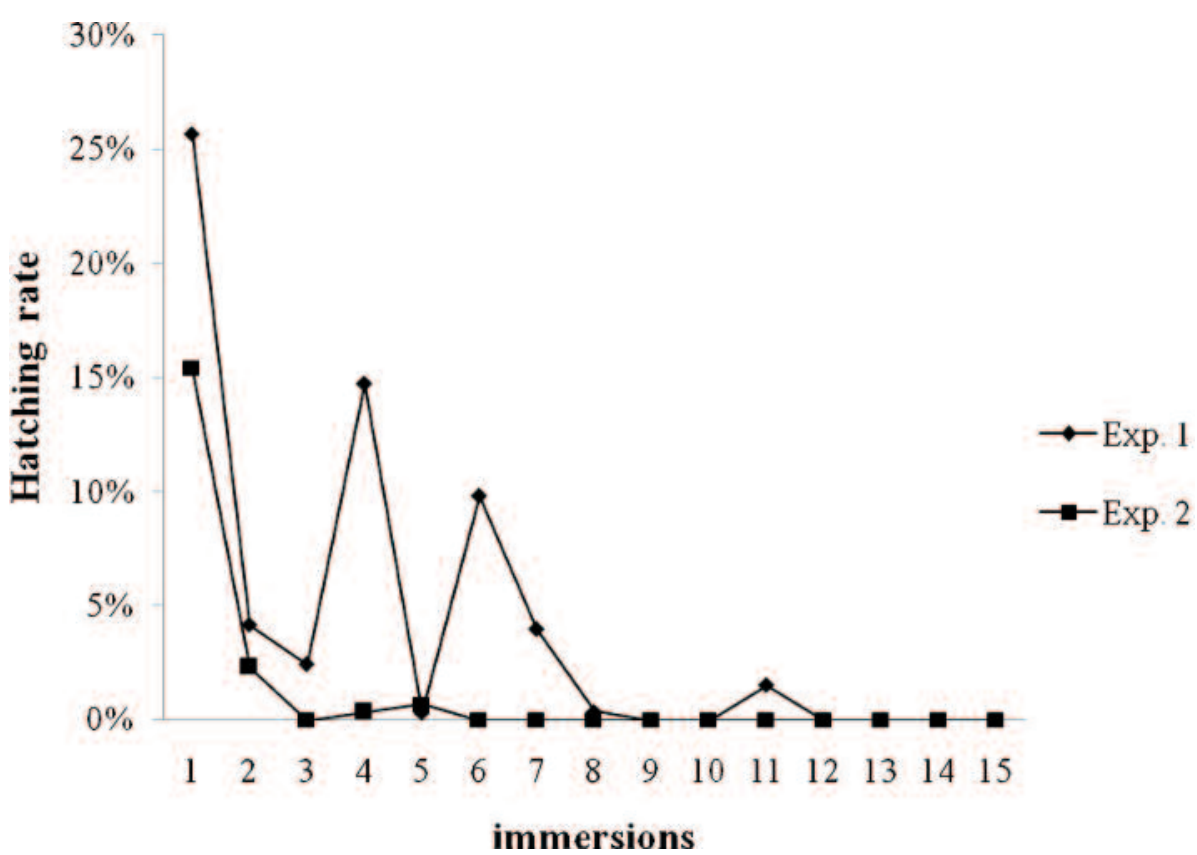

Fig. 2. Hatching rate by immersion of $\mathrm{Hg}$. leucocelaenus eggs collected in ovitraps at the CFMA, Rio de Janeiro, Brazil, during October and November 2015.

\section{DISCUSSION}

The development of an effective vaccine has been successful in reducing the incidence of yellow fever. However, despite the fact that this vaccine has been very important in controlling the disease, data between 1999 and 2009 by the Brazilian national surveillance system revealed that yellow fever shows a seasonal peak in infections during the Southern Hemisphere summer. This seasonality is probably related to the fact that mosquito breeding season peaks in summer, with $93 \%$ of cases identified between November and May (Costa et al., 2010). Thus, studies elucidating the life cycle of $\mathrm{Hg}$. leucocelaenus, considered to be the principal vector in various yellow fever outbreaks in southern and southeastern Brazil (Vasconcelos et al., 2003; Cardoso et al., 2008; Souza et al., 2011), become important for developing suitable control measures.

Our experiments revealed a total viability rate of $36.9 \%$, a result quite similar to that $(36.7 \%)$ reported by Alencar et al. (2014), who considered this hatching percentage to be conservative. The hatching rate of $\mathrm{Hg}$. leucocelaenus in the present study shows variation between the two experiments (months) and immersions, although it was not statistically significant. Results corroborate the observations made by Alencar et al. (2008). The first immersion was shown to result in the most larvae in both experiments. Alencar et al. (2014) obtained immersion 
results similar to ours for $\mathrm{Hg}$. leucocelaenus collected in April, October, and December. The Alencar et al. (2014) study also observed that the third immersion in June provided more impressive results when compared with the other months studied. Although the first immersion was the most successful (highest percentage of eggs hatched), hatching continued for subsequent immersions, as previously observed for $\mathrm{Hg}$. leucocelaenus (Alencar et al., 2014) and for Hg. janthinomys (Alencar et al., 2008). In addition, Campos and Sy (2006) reported that some species require more than one period of contact with water for larvae to hatch after they have been dormant. The mosquito egg diapause is defined as a type of hormonally programmed dormancy, which does not end in an immediate response to favorable conditions. In contrast, quiescence is an induced dormancy that occurs due to unfavorable environmental conditions which terminates immediately after the return of favorable conditions (Denlinger and Armbruster, 2014). The diapause in Aedini eggs generally ends at the first immersion as does Aedes aegypti (Linnaeus, 1762); however, some eggs may require more than one immersion for hatching to occur (Clements, 1963). This is known as "installment hatching" (Gillet, 1955), and is probably a survival strategy of mosquitoes subjected to alternating wet and dry periods (Andreadis, 1990). The genus Haemagogus is an example of mosquitoes utilizing ephemeral breeding habitats.

Although, in our study, there was an abrupt decline in hatchings after the seventh immersion, we measured viability after as many as 11 immersions. The influence of chemical and physiological factors on eggs' viability enables hatching after one or more flooding events, deep enough to submerge the eggs. Multiple immersions of Ochlerotatus albifasciatus eggs (Macquart, 1838) (= Aedes albifasciatus) are affected by the length of the daylight period and temperature (Campos and Sy, 2006). Similarly, Vitek and Livdahl (2006) state that, although Ae. albopictus eggs may require various flooding events before the larvae hatch, the majority hatch during the first two immersions. Thus, eggs of the genus Haemagogus are able to resist long periods of dry conditions that last up to seven months in duration, which allows hatching to occur throughout periods of irregular rainfall (Galindo et al., 1955). The ability of eggs to resist drought and hatch when conditions are more suitable is relevant for managing the epidemiology of wild-type yellow fever, since the peak of transmission coincides with the rainy season (Costa et al., 2010), i.e., the season in which the eggs are exposed to frequent flooding. In addition, it is possible that some eggs are not ready to hatch during a particular rainy season, thus ensuring the presence of an adult population throughout the year.

Forattini (1965) determined that the hatchability of Haemagogus eggs relies on various factors, such as seasonal variation and oxygen content in supporting aquatic habitats. Galindo et al. (1951) emphasized that $\mathrm{Hg}$. janthinomys eggs, collected in Panama, require two weeks of humid conditions in order to develop. However, these results are not supported by the present study in southern Brazil, in which the development time from egg to adult lasted, on average, only 10.44 
$\pm 0.70 \mathrm{~d}$. Alencar et al. (2008) reported studies showing that the Hg. janthinomys life-cycle was completed in $12.40 \pm 0.82 \mathrm{~d}$, demonstrating that development time differs among species of the same genus. A rapid development cycle could also improve the transmissibility of yellow fever, since the shorter life cycle tends to increase the vector's density. Therefore, some life-cycle strategies elucidated in the present study, such as the longevity of $\mathrm{Hg}$. leucocelaenus eggs, the capacity of their eggs to remain in a quiescent state for long periods, and the rate at which new generations are produced, are likely be important in facilitating disease transmission by this species, especially wild-type yellow fever.

By more thoroughly characterizing the biological cycle and hatching rate of Hg. leucocelaenus, as presented here, we hope to contribute new insights into the biology of the species that can be applied toward developing monitoring programs, reducing transmission rates of mosquito-borne diseases, and possibly assist in the development of more efficient eradication strategies.

\section{ACKNOWLEDGMENTS}

We thank the Fundação de Amparo à Pesquisa do Estado do Rio de Janeiro (FAPERJ) (contract no. 111.441/2013) and the Conselho Nacional de Desenvolvimento Científico e Tecnológico-CNPq (301345/2013-9) for their financial support and Coordenação de Aperfeiçoamento de Pessoal de Nível Superior (CAPES), for a research scholarship. Thanks also to Prof. Filipe Vieira S. de Abreu, for his helpful collaboration.

\section{LITERATURE CITED}

Alencar, J., H. M. Almeida, C. B. Marcondes, and A. E. Guimarães. 2008. Effect of multiple immersions on eggs and development of immature forms of Haemagogus janthinomys from South-Eastern Brazil (Diptera: Culicidae). Entomological News 119:239-244.

Alencar, J., R. M. Gleiser, F. Morone, C. F. de Mello, J. dos Santos Silva, N. M. Serra Freire, and A. E. Guimarães. 2014. A comparative study of the effect of multiple immersions on Aedini (Diptera: Culicidae) mosquito eggs with emphasis on sylvan vectors of yellow fever virus. Memórias do Instituto Oswaldo Cruz 109:114-117.

Andreadis, T. G. 1990. Observations on the installment egg hatching in the Brown Salt Marsh mosquito, Aedes cantator. Journal of the American Mosquito Control Association 6:727-729.

Arnell, J. J. 1973. Mosquito studies (Diptera, Culicidae). XXXII. A revision of the genus Haemagogus. Contributions of the American Entomological Institute 10:1-174.

Campos, R. E. and V. E. Sy. 2006. Variation in the hatching response of Ochlerotatus albifasciatus egg batches (Diptera: Culicidae) in temperate Argentina. Memórias do Instituto Oswaldo Cruz 101:47-53.

Cardoso, J. C., M. A. B. Almeida, E. Santos, D. F. Fonseca, M. A. M. Sallum, C. A. Noll, H. A. O. Monteiro, A. C. R. Cruz, V. L. Carvalho, E. V. Pinto, F. C. Castro, J. P. N. Neto, M. N. O. Segura, and P. F. C. Vasconcelos. 2010. Yellow fever virus in Haemagogus lencocelaenus and Aedes serratus mosquitoes, Southern Brazil, 2008. Emerging Infectious Diseases 16:19181924. 
Chadee, D. D., R. Ganesh, J. O. Hingwan, and E. S. Tikasingh. 1995. Seasonal abundance, biting cycle and parity of the mosquito Haemagogus leucocelaenus in Trinidad, West Indies. Medical and Veterinary Entomology 9:372-376.

Clements, A. N. 1992. Biology of Mosquitoes, Vol. I: Development, Nutrition, Reproduction. Chapman \& Hall, London, United Kingdom. pp. 380-407.

Clements, A. N. 1963. The physiology of mosquitoes. International Series of Monographs on Pure and Applied Biology. Zoology Division. Pergamon Press. Vol. 17. Oxford, England, United Kingdom. 393 pp.

Costa, Z. G. A., A. P. M. Romano, A. N. M. Elkhoury and B. Flannery. 2010. Evolução histórica da vigilância epidemiológica e do controle da febre amarela no Brasil. Revista Pan-Amazônica de Saúde 2(1):11-26.

Denlinger, D. L. and P. A. Armbruster. 2014. Mosquito Diapause. Annual Review of Entomology 59:73-93.

Fay, R. W. and D. A. Eliason. 1966. A preferred oviposition site as a surveillance method for Aedes aegypti. Mosquito News 26:531-535.

Fay, R. W. and A. S. Perry. 1965. Laboratory studies of ovipostional preferences of Aedes aegypti. Mosquito News 25:276-81.

Figueiredo, M. L., A. C. Gomes, A. A. Amarilla, A. S. Leandro, A. S. Orrico, R. F. Araujo, J. S. M. Castro, E. L. Durigon, V. H. Aquino, and L. T. M. Figueiredo. 2010. Mosquitoes infected with dengue viruses in Brazil. Virology Journal 12:152.

Fiocruz. 2010. Relatório Ambiental do Setor 1 da Colônia Juliano Moreira. Rio de Janeiro.

Forattini, O. P. 1965. Entomologia Médica. 3rd vol., Faculdade de Saúde Pública, Universidade de São Paulo, São Paulo. 416 pp.

Forattini, O. P., A. C. Gomes, Id. Natal, I. Kakitani, and D. Marucci. 1988. Preferências alimentares e domiciliação de mosquitos Culicidae no Vale do Ribeira, São Paulo, Brasil, com especial referência a Aedes scapularis e a Culex (Melanoconion). Revista de Saúde Pública 23:9-19.

Forattini, O. P. 2002. Culicidologia Médica. 2rd vol., Faculdade de Saúde Pública, Universidade de São Paulo, São Paulo. 860 pp.

Galindo, P., S. J. Carpenter, and H. Trapido. 1951. Ecological observations on forest mosquitoes of an endemic yellow-fever area in Panama. American Journal of Tropical Medicine and Hygiene 31:98-137.

Galindo P., S. J. Carpenter, and H. Trapido. 1955. A contribution to the ecology and biology of tree hole breeding mosquitoes of Panama. Annals of the Entomological Society of America 48: 158-164.

Gillett, J. D. 1955. Variation in the hatching response of Aedes eggs (Diptera: Culicidae). Bulletin of Entomological Research 46:241-254.

Haddow, A. J. 1954. Studies of the biting-habits of African mosquitoes. An appraisal of methods employed, with special to the twenty-four hours. Bulletin of Entomological Research 145:199242.

Haddow, A. J. 1960. Studies on the biting-habits and medical importance of east African mosquitoes in the genus Aedes. I - Subgenera Aedimorphus, Bankisinella and Dunnius. Bulletin of Entomological Research 50:759-779. 
Juliano, A. S. and L. P. Lounibos. 2005. Ecology of invasive mosquitoes: effects on resident species and on human health. Ecology Letters 8:558-574.

Marcondes, C. B. and J. Alencar. 2010. Revisão de mosquitos Haemagogus Williston (Diptera: Culicidae) do Brasil. Reviews in Biomedical Engineering 21:221-238.

Silver, J. B. 2008. Mosquito ecology: field sampling methods, 3rd edition. Springer, New York. $1477 \mathrm{pp}$

Souza, R. P., S. Petrella, T. L. M. Coimbra, A. Y. Maeda, I. M. Rocco, I. Bisordi, V. R. Silveira, L. E. Pereira, A. Suzuki, S. J. S. Silva, F. G. Silva, F. S. Salvador, R. M. Tubaki, R. T. Menezes, M. Pereira, E. S. Bergo, R. C. Hoffmann, R. M. F. Spinola, C. H. Tengan, and M. M. Siciliano. 2011. Isolation of yellow fever virus (YFV) from naturally infected Haemagogus (Conopostegus) leucocelaenus (diptera, culicidae) in São Paulo State, Brazil, 2009. Revista Do Instituto De Medicina Tropical De Sao Paulo 53(3):133-139.

Vasconcelos, P. F. C., A. F. Sperb, H. A. O. Monteiro, M. A. N. Torres, M. R. S. Souza, H. B. Vasconcelos, L. B. L. F. Mardini, and S. G. Rodrigues. 2003. Isolations of yellow fever virus from Haemagogus leucocelaenus in Rio Grande do Sul State, Brazil, in the Southern Cone. Transactions of the Royal Society of Tropical Medicine and Hygiene 97:60-2.

Vinogradova, E. B. 2007. Diapause in aquatic insects, with emphasis on mosquitoes. Diapause in aquatic invertebrates, theory and human use. New York. Springer-Verlag. pp. 83-113.

Vitek, C. J. and T. P. Livdahl. 2006. Field and laboratory comparison of hatch rates in Aedes albopictus (Skuse). Journal of the American Mosquito Control Association 22(4):609-614. 